\title{
Pengaruh Penerapan Pembelajaran Blended Cooperative E-Learning Terhadap Self-Efficacy dan Curiosity Siswa dalam Pelajaran Fisika di SMA Karuna Dipa Palu
}

\author{
Muhammad Jarnawi, Ketut Alit Adi Untara \\ i.am.jarnawi@gmail.com \\ Program Studi Pendidikan Fisika FKIP Universitas Tadulako \\ Jl. Soekarno Hatta Km. 9 Kampus Bumi Tadulako Tondo Palu - Sulawesi Tengah
}

\begin{abstract}
Penelitian ini bertujuan untuk mengetahui pengaruh penerapan pembelajaran blended cooperative e-learning terhadap self-efficacy dan curiosity siswa dalam pelajaran fisika di SMA Karuna Dipa Palu sampel terdiri dari 20 siswa, 10 siswa pada kelas eksperimen dan 10 siswa pada kelas kontrol. Data penelitian ini diambil dengan menggunakan angket, tes tertulis lembar observasi serta dokumentasi. Data utama diambil dengan menggunakan angket self-efficacy, angket curiosity serta tes tertulis. Angket self-efficacy digunakan untuk mengambil tanggapan kepercayaan diri siswa, angket curiosity digunakan untuk mengambil tanggapan rasa ingin tahu siswa dari pengaruh pelaksanaan pembelajaran blended cooperative e-learning sedangkan tes tertulis digunakan untuk mengambil data hasil belajar siswa. Lembar observasi dan dokumentasi digunakan sebagai data pendukung. Pengolahan data dilakukan dengan menggunakan uji-t rerata melalui analisis statistical product and service solution. Nilai sig yang digunakan sebesar (sig) 0,05. Dari hasil penelitian diperoleh kesimpulan bahwa: 1) terdapat pengaruh yang signifikan dari penerapan pembelajaran blended cooperative e-learning terhadap selfefficacy dan curiosity siswa, 2) terdapat pengaruh yang signifikan dari penerapan pembelajaran blended cooperative e-learning terhadap hasil belajar siswa.
\end{abstract}

Kata Kunci : Blended Cooperative e-learning, Self-efficacy, Curiosity, Hasil Belajar

\section{PENDAHULUAN}

Fisika Hasil wawancara yang dilakukan pada siswa-siswa di SMA Karuna Dipa Palu mengenai pelajaran yang sulit dipahami atau membosankan maka diperoleh data yang salah satunya adalah pelajaran fisika. Tidak dapat dipungkiri pelajaran fisika merupakan momok bagi siswa. Metode konvensional pembelajaran langsung yang sering digunakan tidak menarik, guru belum maksimal memahami konsep dan penekanan pada jiwa siswa akibatnya selfefficacy siswa mengalami penurunan serta rendahnya motivasi siswa untuk mengikuti pelajaran fisika. Jika hanya sebagian siswa yang memperoleh nilai tinggi pada evaluasi yang diberikan, maka dapat dipahami siswa tersebut memiliki tingkat pemikiran di atas rata-rata, keseriusan, percaya diri dan motivasi kecintaanya yang besar untuk mempelajari ilmu fisika dan sebagaian lagi didasari atas keterpaksaan belajar agar memperoleh nilai di atas rata-rata dan bukan atas pemahaman esensi ilmu fisika tersebut.

Dari wawancara dengan dasar kesukaan diperoleh bahwa siswa lebih suka pelajaran pendidikan jasmani kesehatan jika dibandingkan ilmu-ilmu sains. Alasan dasar adalah siswa lebih senang bermain berkelompok dan menyelesaikan masalah bersama. Jika dilihat dari kepercayaan diri siswa atau self-efficacy siswa maka dapat ditarik kesimpulan bahwa penyebab dasar seorang siswa tidak memiliki motivasi belajar fisika adalah rendahnya self-efficacy siswa. Selain hal tersebut penyebab lainnya adalah kemauan untuk belajar atau motivasi belajar yang rendah ini lebih sepesifik lagi bahwa curiosity siswa rendah.

Bandura (1997) menjelaskan self-efficacy adalah keyakinan seorang individu mengenai kemampuannya dalam mengorganisasi dan menyelesaikan suatu tugas yang diperlukan untuk mencapai hasil tertentu. Self-efficacy siswa yakni keyakinan bahwa seseorang siswa bisa menguasai situasi dan mendapatkan hasil positif. Self-efficacy berpengaruh besar terhadap perilaku seorang siswa. Seorang siswa yang selfefficacynya rendah tidak mau berusaha belajar untuk mengerjakan ujian karena tidak percaya bahwa belajar akan bisa membantunya mengerjakan soal.

Bandura (1997) mengemukakan beberapa dimensi dari self-efficacy, yaitu magnitude, generality, dan strength. Magnitude, berkaitan dengan tingkat kesulitan suatu tugas yang dilakukan. Generality, berkaitan dengan bidang 
tugas, seberapa luas individu mempunyai keyakinan dalam melaksanakan tugas-tugas. Strength, berkaitan dengan kuat lemahnya keyakinan seorang individu.

Self-efficacy dapat diperoleh, diubah, ditingkatkan atau diturunkan, melalui salah satu atau kombinasi empat sumber, yakni pengalaman menguasai sesuatu prestasi (performance accomplishment), pengalaman vikarius (vicarious experiences), persuasi sosial (social persuation) dan pembangkitan emosi (emotional/physiological states). Pengalaman performansi adalah prestasi yang pernah dicapai pada masa yang telah lalu. Pengalaman vikarius diperoleh melalui model sosial. Persuasi sosial adalah rasa percaya siswa kepada pemberi persuasi, dan sifat realistik dari apa yang dipersuasikan.

Self-efficacy diduga akan mempengaruhi self regulated learning. Siswa yang memiliki selfefficacy yang tinggi akan memiliki keyakinan mengenai kemampuannya dalam mengorganisasi dan menyelesaikan suatu tugas yang diperlukan untuk mencapai hasil tertentu dalam berbagai bentuk dan tingkat kesulitan. Hal ini berdampak self-regulated learning juga akan tinggi. siswa akan mampu mengelola secara efektif pengalaman belajarnya sendiri di dalam berbagai cara sehingga mencapai hasil belajar yang optimal. Self-efficacy yang rendah akan sangat mempengaruhi siswa dalam menyelesaikan tugasnya untuk mencapai hasil tertentu. Hal ini dapat dikaitkan dengan kurangnya informasi tentang kemampuan para siswa untuk yakin pada dirinya sendiri dalam mengerjakan tugas yang diberikan kepada mereka.

Selain dari pengaruh self-efficacy peningkatan hasil belajar juga dipengaruhi oleh curiosity siswa. Davies dalam Murtadlo (2011) menjelaskan bahwa bagi seorang siswa, curiosity menyebabkan siswa memiliki semangat belajar. Dalam hal ini, curiosity siswa terlihat pada fenomena-fenomena yang melekat kepadanya, misalnya siswa menjadi aktif, sibuk, dan tertarik untuk melakukan tugas-tugas belajar. Ini berarti siswa terus aktif melakukan berbagai upaya atau usaha untuk meningkatkan keberhasilan perolehan belajarnya sampai memperoleh hasil belajar yang cukup memuaskan sebagaimana yang diharapkan.

Usaha untuk meningkatkan hasil belajar menurut Gredler dalam Murtadlo (2011), merupakan atribusi intrinsik untuk memperoleh kesuksesan atau menghindari kegagalan. Siswa yang bermotivasi belajar tinggi (motivasi berprestasi) akan melakukan upaya-upaya atau usaha dengan frekuensi dan intensitas yang tinggi. Bila hal ini terjadi, maka keberhasilan belajar siswa akan terjadi. Dengan kata lain siswa yang bermotivasi tinggi dalam belajar memungkinkan akan memperoleh hasil belajar yang tinggi pula. Semakin tinggi motivasinya, semakin intensitas usaha dan upaya yang dilakukan, maka semakin tinggi hasil belajar yang diperolehnya.

Motivasi yang didasari rasa ingin tahu atau curiosity akan mengarahkan dan mengendalikan tujuan belajar siswa. Siswa yang bermotivasi mampu mengarahkan dirinya untuk melengkapi tugas-tugas, memungkinkan ia mencapai tujuan belajar yang diinginkan baik tujuan pembelajaran sebagaimana yang diformulasikan oleh guru dalam persiapan pembelajaran, maupun tujuan khusus yang ditetapkan dirinya sendiri. Hal ini menjadikan siswa terarah dalam berperilaku belajar. Proses pembelajaran itu bergerak dinamis, dan selalu mengarah untuk pencapaian tujuan pembelajaran. Motivasi belajar siswa mendorong perilaku belajar siswa agar lebih dinamis dan terarah untuk mencapai tujuan pembelajaran secara efektif (Davies dalam Murtadlo, 2011).

Begitu pentingnya self-efficacy dan curiosity siswa maka perlu upaya nyata yang harus dilakukan untuk meningkatkanya baik dengan menggunakan model pembelajaran terbaru maupun menggabungkan beberapa model inovatif yang telah ada. Model yang digunakan harus manarik keingian siswa untuk belajar sekaligus mencintai pembelajaran fisika yang diberikan. Selain hal ini model yang digunakan juga harus mampu menciptakan suasana sosial yang saling mendukung antar siswa agar self-efficacy dan curiosity siswa meningkat.

Berdasarkan permasalahan ini peneliti tertarik untuk mengkaji penggunaan model pembelajaran e-learning yang digabungkan dengan model kooperatif atau model blended cooperative e-learning. Penggunaan model elearning diharapkan dapat meningkatkan minat belajar dan rasa ingin tahu siswa. Sedangkan penggunaan model kooperatif diharapkan dapat meningkatkan dukungan sosial antar siswa dalam memecahkan suatu permasalahan yang diberikan. Penggunaan cooperative e-learning ini akan membentuk tiga interaksi penting yaitu interaksi sosial, interaksi muatan dan interaksi guru. Interaksi sosial merupakan interaksi sesama siswa dalam memecahkan masalah. Interaksi muatan adalah interaksi yang menghubungkan konsep-konsep pembelajaran pada proses kognitif siswa. Sedangkan interaksi guru adalah interaksi yang memungkinkan guru 
sebagai pengatur dan fasilitator pada tahapan proses pembelajaran. Dari penerapan model ini diharapkan dapat meningkatkan self-efficacy dan curiosity siswa dan pada akhirnya meningkatkan hasil belajar siswa.

\subsection{Rumusan Masalah}

Berdasarkan latar belakang di atas maka dapat dirumuskan permasalahan sebagai berikut:

1) Apakah ada pengaruh penerapan pembelajaran blended cooperative e-learning terhadap self-efficacy dan curiosity siswa.

2) Apakah ada pengaruh penerapan pembelajaran blended cooperative e-learning terhadap hasil belajar siswa.

\subsection{Tujuan Penelitian}

Berdasarkan permasalahan di atas maka secara umum tujuan penelitian ini adalah:

1) Untuk menjelaskan pengaruh penerapan pembelajaran blended cooperative $e$ learning terhadap self-efficacy dan curiosity siswa.

2) Untuk menjelaskan pengaruh penerapan pembelajaran blended cooperative e-learning terhadap hasil belajar siswa.

\subsection{Manfaat Penelitian}

Manfaat yang diharapkan dalam penelitian ini adalah sebagai berikut:

1) Bagi guru, tersedia model pembelajaran blended cooperative e-learning yang dapat digunakan oleh guru dalam mengelolah kegiatan belajar mengajar.

2) Bagi siswa, untuk mengubah self-efficacy dan curiosity dalam kegiatan pembelajaran serta meningkatkan hasil belajar siswa.

3) Bagi sekolah, menjadi bahan informasi yang dapat dijadikan pedoman penggunaan pembelajaran blended cooperative e-learning dalam rangka meningkatkan mutu pendidikan.

4) Bagi peneliti, menghasilkan perangkat pembelajaran blended cooperativ e-learning yang dapat mengubah self-efficacy dan curiosity siswa sekaligus dapat dikomersilkan.

\section{METODE PENELITIAN}

\subsection{Jenis Penelitian}

Metode yang digunakan dalam penelitian ini adalah metode eksperimen kuasi. Pengumpulan data yang dilakukan dalam penelitian ini dimaksudkan untuk mengumpulkan data atau informasi mengenai variabel-variabel dalam penelitian dan data pendukung lainnya.

\subsection{Lokasi dan Waktu Penelitian}

Lokasi penelitian ini adalah di SMA Karuna Dipa Palu, Penelitian dilakukan pada bulan Maret 2016 sampai dengan Juli 2016.

\subsection{Populasi dan Sampel}

Populasi dalam penelitian adalah seluruh siswa kelas X SMA Karuna Dipa Palu yang tersebar dalam 2 kelas. Sampel penelitian yang diambil adalah kelas XA untuk kelas eksperimen dengan jumlah 20 orang siswa, dan kelas XB untuk kelas kontrol dengan jumlah peserta didik 18 orang. Sampel dipilih dengan cara purposive sampling dengan kriteria bahwa kelas XA dan XB memiliki kemampuan yang homogen atau kemampuan rata-rata pada kedua kelas adalah sama.

\subsection{Definisi Operasional Variabel}

Definisi operasional digunakan untuk memberikan batasan arti suatu variabel dengan merinci hal yang harus dikerjakan oleh peneliti untuk mengukur

varibel tersebut.

1) Variabel pembelajaran blended cooperative e-learning.

2) Variabel self-efficacy.

3) Variabel curiosity.

4) Variabel hasil belajar.

\subsection{Desain Penelitian}

Penelitian ini menggunakan metode penelitian eksperimen kuasi, dengan desain penelitian Nonequivalent control group pre-test and post-test design (Sugiyono, 2007).

\subsection{Instrumen Penelitian}

Instrumen digunakan untuk memperoleh data dalam penelitian. Bentuk-bentuk istrumen yang digunakan yaitu sebagai berikut:

\section{1) Tes}

Tahapan penyusunan tes, diawali dengan penyusunan kisi-kisi yang mencakup kompetensi dasar, indikator, indikator yang diukur beserta skor penilaiannya dan nomor butir soal beserta kunci jawabannya dan aturan pemberian skor untuk masing-masing butir soal.

\section{2) Angket Self-efficacy}

Angket ini digunakan untuk mengukur data self-efficacy. Instrumen angket untuk mengukur self-efficacy berpedoman pada skala yang dikembangkan oleh Bandura (1997), yaitu guide for constructing selfefficacy scales.

\section{3) Angket Curiosity}

Angket ini digunakan untuk melihat curiosity siswa pada saat pelaksanaan kegiatan pembelajaran. Analisis yang 
digunakan mengikuti analisis angket curiosity.

\section{4) Lembar Observasi}

Lembar observasi digunakan untuk melihat bagaimana keterlibatan siswa selama proses pembelajaran dan dilakukan oleh guru pendamping. Data dari lembar observasi yang terkumpul selanjutnya dikelompokkan dengan menggunakan skala lima berdasarkan teknik kategori yang telah ditetapkan.

\subsection{Teknik Analisa Data}

\section{a. Uji normalitas}

Uji normalitas atau uji kenormalan distribusi data dapat dihitung dengan menerapkan persamaan Kolmogorovsimirnov dan Shapiro-wilk.

\section{b. Uji homogenitas}

Uji homogenitas digunakan untuk melihat varians data antara dua sampel data yang dianalisis.

\section{c. Uji hipotesis}

Uji hipotesis penelitian dilakukan dengan menganalisis tingkat signifikan perbedaan dua rata-rata hasil belajar, self-efficacy dan curiosity antara kelas eksperimen dan kelas kontrol sebelum dan sesudah pelaksanaan pembelajaran dilakukan.

\section{HASIL dan PEMBAHASAN}

\subsection{Deskripsi populasi dan sampel penelitian}

Tahap awal pelaksanaan penelitian, dilakukan pengujian soal di kelas XI IPA 2 SMA Negeri 1 Palu dengan jumlah 40 butir soal dan setelah dianalisis maka diperoleh 25 soal yang sesuai dan akan digunakan pada penelitian. Selain pengujian butir soal juga dipersiapkan seluruh perangkat pembelajaran baik lembar kerja siswa, perangkat pembelajaran komputer, animasi simulasi, rpp, silabus yang keseluruhannya dilakukan validasi tim ahli. Pada pelaksanaan penelitian, dengan menggunakan teknik sampling purposive maka diambil dua kelas sebagai sampel penelitian yaitu kelas XA dan XB. Kelas XA sebagai kelas eksperimen dan kelas XB sebagai kelas kontrol. Untuk XA, jumlah siswa yang digunakan untuk objek penelitian sebanyak 20 siswa. Untuk kelas XB, jumlah siswa yang digunakan untuk objek penelitian sebanyak 18 siswa. Pengambilan sampel ini berdasarkan pertimbangan bahwa kedua kelas memiliki kemampuan rata-rata sama.

\subsection{Deskripsi data}

Deskripsi data disajikan untuk memberikan gambaran umum mengenai penyebaran data dari penelitian. Data yang disajikan berupa data mentah yang diolah menggunakan teknik statistik dengan menggunakan bantuan sofware SPSS. Penggunaan SPSS memiliki tujuan agar pengolahan data tidak mengalami humaneror. Data yang diolah dalam penelitian terdiri dari tiga variabel yaitu variabel self-efficacy, curiosity dan variabel hasil belajar. Pada pelaksanaannya akan dilihat sejauh mana penerapan pembelajaran blended cooperative elearning mempengaruhi self-efficacy dan curiosity melalui analisis hasil belajar.

\subsection{Pengujian instrumen}

Proses validasi seluruh instrumen dibagi dalam beberapa bagian yaitu pemeriksaan tim ahli (validator) untuk memeriksa kelayakan penerapan perangkat pembelajaran. Pada instrumen tes dilakukan validasi, validasi dilakukan untuk mengetahui dan memperbaiki tes yang akan digunakan untuk penelitian. Untuk instrumen angket, validasi dilakukan pada sumber angket dengan perubahan beberapa kalimat sehingga sesuai dengan pengukuran selfefficacy dan curiosity. .

\subsection{Pengujian persyaratan analisis}

\section{1) Uji normalitas}

Uji normalitas merupakan salah satu uji asumsi yang harus dipenuhi sebagai sarat penggunaan teknik statistik parametrik. Uji normalitas data dilakukan dengan menggunakan uji Kolmogorov-simirnov dan Shapiro-wilk. Penggunaan uji Kolmogorovsimirnov dan Shapiro-wilk didasari oleh kelebihan dari uji ini yaitu sederhana dan tidak menimbulkan perbedaan persepsi di antara satu pengamat dengan pengamat yang lain, yang sering terjadi pada uji normalitas dengan menggunakan grafik. Konsep dasar dari uji normalitas Kolmogorov Smirnov dan Shapiro-wilk adalah dengan membandingkan distribusi data (yang akan diuji normalitasnya) dengan distribusi normal baku. Hasil uji Kolmogorov-simirnov dan Shapiro-wilk dapat dilihat pada Tabel 3.1 dan Tabel 3.2.

a. Normalitas data hasil belajar, selfefficacy dan curiosity kelas eksperimen. 
Tabel 3.1 Normalitas Data Kelas Eksperimen

\begin{tabular}{|c|c|c|c|}
\hline Komponen & $\begin{array}{c}\text { Self- } \\
\text { efficacy }\end{array}$ & Curiosity & $\begin{array}{c}\text { Hasil } \\
\text { belajar }\end{array}$ \\
\hline $\begin{array}{c}\text { Kolmogorov- } \\
\text { Smirnova (sig) }\end{array}$ & 0,200 & 0,200 & 0,446 \\
\hline $\begin{array}{c}\text { Shapiro-Wilk } \\
\text { (sig) }\end{array}$ & 0,070 & 0,523 & 0,181 \\
\hline Kesimpulan & Normal & Normal & Normal \\
\hline
\end{tabular}

b. Normalitas Data Hasil Belajar, selfefficacy dan curiosity Kelas Kontrol. Tabel 3.2 Normalitas Data Kelas Kontrol

\begin{tabular}{|c|c|c|c|}
\hline Komponen & $\begin{array}{c}\text { Self- } \\
\text { efficacy }\end{array}$ & Curiosity & $\begin{array}{c}\text { Hasil } \\
\text { belajar }\end{array}$ \\
\hline $\begin{array}{c}\text { Kolmogorov- } \\
\text { Smirnova (sig) }\end{array}$ & 0,20 & 0,20 & 0,20 \\
\hline $\begin{array}{c}\text { Shapiro-Wilk } \\
\text { (sig) }\end{array}$ & 0,208 & 0,984 & 0,602 \\
\hline Kesimpulan & Normal & Normal & Normal \\
\hline
\end{tabular}

Hasil analisis Kolmogorov-simirnov dan Shapiro-wilk pada Tabel 3.1 dan Tabel 3.2 memberikan gambaran bahwa self-efficacy, curiosity dan hasil belajar pada kelas eksperimen dan kelas kontrol adalah terdistribusi normal hal ini didasarkan pada nilai sig masing-masing variabel $>$ sig 0,05.

2) Uji homogenitas

Hasil uji homogenitas antara pretest kelas eksperimen dan kelas kontrol dengan menggunakan SPSS diperoleh sesuai Tabel 3.3.

Tabel 3.3 Analisis Homogenitas Pretest

\begin{tabular}{|c|c|c|c|}
\hline $\begin{array}{c}\text { Levene } \\
\text { Statistic }\end{array}$ & df1 & df2 & Sig. \\
\hline 0,227 & 1 & 36 & 0.637 \\
\hline \multirow{2}{*}{ Anova } & \multicolumn{2}{|c|}{ F } & Sig \\
\cline { 2 - 4 } & \multicolumn{2}{|c|}{0,231} & 0,633 \\
\hline
\end{tabular}

Hasil uji homogenitas sesuai Tabel 3.3 memberikan gambaran bahwa data pretest kelas eksperimen dan kelas kontrol adalah homogen hal ini didasakan atas nilai sig $0,637>$ probabilitas 0,05 .

\subsection{Hasil Analisis Data Penelitian}

a. Uji perbedaan rerata pretest postest kelas kontrol dan kelas eksperimen

Hasil uji perbedaan rerata pretest postest kelas kontrol dan kelas eksperimen dapat dilihat pada Tabel 3.4 dan Tabel 3.5.

Tabel 3.4 Uji Perbedaan Rerata Pretest Kelas Eksperimen dan Kontrol

\begin{tabular}{|c|c|c|c|c|c|c|}
\hline & \multicolumn{3}{|c|}{$\begin{array}{c}\text { Levene's Test for } \\
\text { Equality of Variances }\end{array}$} & \multicolumn{3}{|c|}{$\begin{array}{c}\text { t-test for Equality of } \\
\text { Means }\end{array}$} \\
\hline & $\mathrm{N}$ & $\mathrm{F}$ & $\mathrm{sig}$ & $\mathrm{t}$ & $\mathrm{df}$ & $\begin{array}{c}\text { sig (2- } \\
\text { tailed) }\end{array}$ \\
\hline $\begin{array}{c}\text { eksperi } \\
\text { men } \\
\text { kontrol }\end{array}$ & 20 & 0.227 & 0,637 & $-0,48$ & 36 & 0,63 \\
\hline
\end{tabular}

Tabel 3.5 Uji Perbedaan Rerata Postest Kelas Eksperimen dan Kontrol

\begin{tabular}{|c|c|c|c|c|c|c|}
\hline & \multicolumn{3}{|c|}{$\begin{array}{c}\text { Levene's Test for } \\
\text { Equality of } \\
\text { Variances }\end{array}$} & \multicolumn{3}{|c|}{$\begin{array}{c}\text { t-test for Equality } \\
\text { of Means }\end{array}$} \\
\hline & $\mathrm{N}$ & $\mathrm{F}$ & $\mathrm{sig}$ & $\mathrm{t}$ & $\mathrm{df}$ & $\begin{array}{c}\text { sig } \\
(2- \\
\text { tailed } \\
)\end{array}$ \\
\hline $\begin{array}{c}\text { eksperime } \\
\mathrm{n} \\
\text { kontrol }\end{array}$ & 20 & 0.002 & 0,969 & 5,02 & 36 & 0,00 \\
\hline
\end{tabular}

hasil perbedaan rerata pretest pada kelas eksperimen dan kelas kontrol sesuai Tabel 3.4 diperoleh nilai sig 0,63> probabilitas 0,05 . Hal ini memberikan pernyataan bahwa tidak terdapat perbedaan antara pretest kelas eksperimen dan pretest kelas kontrol. Sedangkan hasil perbedaan rerata postest pada kelas eksperimen dan kelas kontrol sesuai Tabel 3.5 diperoleh nilai sig $0,00<$ probabilitas 0,05 . Hal ini memberikan pernyataan bahwa terdapat perbedaan antara postest kelas eksperimen dan postest kelas kontrol.

Untuk nilai rata-rata dan standar deviasi, hasil analisis memperlihatkan bahwa nilai ratarata pretest untuk kelas eksperimen sebesar 68,20 dan nilai rata-rata pretest untuk kelas kontrol sebesar 69,55. Setelah dilakukan pelaksanaan pembelajaran blended cooperative e-learning terjadi perubahan rata-rata nilai postest.Nilai rata-rata postest untuk kelas eksperimen meningkat menjadi 80,40 sedangkan untuk kelas kontrol menjadi 67,11. Hasil analisis deviasi menghasilkan nilai standar deviasi pretest untuk kelas eksperimen sebesar 9,12 dan untuk kelas kontrol sebesar 8,13. Setelah dilakukan pelaksanaan pembelajaran blended cooperative e-elearning terjadi perubahan nilai standar deviasi postest. Nilai standar deviasi postest untuk kelas eksperimen menjadi 7,88 sedangkan untuk kelas kontrol menjadi 8,40 .

\section{b. Uji perbedaan rerata self-efficacy dan curiosity}

Hasil analisis berbantuan SPSS diperoleh data perbedaan rerata self-efficacy dan curiosity antara pembelajaran pada kelas eksperimen dan kelas kontrol dapat dilihat pada Tabel 3.6 dan Tabel 3.7.

Tabel 3.6 Uji Perbedaan Rerata Self-Efficacy Kelas Eksperimen dan Kontrol

\begin{tabular}{|c|c|c|c|c|c|c|}
\hline & \multicolumn{2}{|c|}{$\begin{array}{c}\text { Levene's Test for } \\
\text { Equality of Variances }\end{array}$} & \multicolumn{3}{|c|}{$\begin{array}{c}\text { t-test for Equality of } \\
\text { Means }\end{array}$} \\
\hline & $\mathrm{N}$ & $\mathrm{F}$ & $\mathrm{sig}$ & $\mathrm{t}$ & $\mathrm{df}$ & $\begin{array}{c}\text { sig (2- } \\
\text { tailed) }\end{array}$ \\
\hline $\begin{array}{c}\text { eksper } \\
\text { imen } \\
\text { kontro } \\
\text { I }\end{array}$ & 20 & 0,02 & 0,97 & $\begin{array}{c}5,0 \\
3\end{array}$ & 36 & 0,00 \\
\hline
\end{tabular}


Tabel 3.7 Uji Perbedaan Rerata Curiosity Kelas Eksperimen dan Kontrol

\begin{tabular}{|c|c|c|c|c|c|c|}
\hline & \multicolumn{2}{|c|}{$\begin{array}{c}\text { Levene's Test for } \\
\text { Equality of Variances }\end{array}$} & \multicolumn{3}{|c|}{$\begin{array}{c}\text { t-test for Equality of } \\
\text { Means }\end{array}$} \\
\hline & $\mathrm{N}$ & $\mathrm{F}$ & $\mathrm{sig}$ & $\mathrm{t}$ & $\mathrm{df}$ & $\begin{array}{c}\text { sig (2- } \\
\text { tailed) }\end{array}$ \\
\hline $\begin{array}{c}\text { eksperim } \\
\text { en } \\
\text { kontrol }\end{array}$ & 20 & 6,02 & $\begin{array}{c}0,01 \\
8\end{array}$ & $\begin{array}{c}3,6 \\
2\end{array}$ & 36 & 0,001 \\
\hline
\end{tabular}

Data hasil perbedaan rerata self-efficacy kelas eksperimen dan kelas kontrol sesuai Tabel 3.6 diperoleh nilai sig $0,00<$ probabilitas 0,05 . $\mathrm{Hal}$ ini memberikan pernyataan bahwa terdapat perbedaan antara self-efficacy kelas eksperimen dan self-efficacy kelas kontrol. Data hasil perbedaan rerata curiosity kelas eksperimen dan kelas kontrol sesuai Tabel 3.7 diperoleh nilai sig $0,001<$ probabilitas 0,05 ini memberikan pernyataan bahwa terdapat perbedaan antara curiosity kelas eksperimen dan curiosity kelas kontrol.

Hasil analisis nilai rata-rata dan standar
deviasi Self-Efficacy dan Curiosity memperlihatkan bahwa nilai rata-rata angket self-efficacy untuk kelas eksperimen sebesar 107,45 dengan standar deviasi 9,31 dan nilai rata-rata angket self-efficacy untuk kelas kontrol sebesar 103,00 dengan standar deviasi 8,00. Sedangkan untuk nilai rata-rata angket curiosity untuk kelas eksperimen meningkat sebesar 115,50 dengan standar deviasi 13,35, sedangkan untuk kelas kontrol sebesar 102,27 dengan standar deviasi 8,25. Analisis rata-rata serta standar deviasi ini memberikan gambaran bahwa pelaksanaan pembelajaran blended cooperative e-learning lebih meningkatkan selfefficacy dan curiosity siswa jika dibandingkan pelaksanaan pembelajaran konvesional

\section{KESIMPULAN}

Berdasarkan pembahasan dan analisis dapat ditarik beberapa kesimpulan sebagai berikut :

a. Terdapat pengaruh yang signifikan dari penerapan pembelajaran blended cooperative e-learning terhadap selfefficacy dan curiosity siswa. Pengaruh ini dibuktikan dengan adanya perbedaan nilai self-efficacy dan curiosity antara siswa yang mengikuti pembelajaran blended cooperative e-learning dengan siswa yang mengikuti pembelajaran konfesional. Dari analisis uji-t rerata self-efficacy diperoleh nilai signifikan (sig) $0,02<0,05$, sedangkan pada uji-t rerata curiosity diperoleh nilai signifikansi ( $\operatorname{sig})$ 0,04 < 0,05 .

b. Terdapat pengaruh yang signifikan dari penerapan pembelajaran blended cooperative e-learning terhadap hasil belajar siswa. Pengaruh ini dibuktikan dengan adanya perbedaan hasil belajar siswa yang mengikuti pembelajaran blended cooperative e-learning dengan siswa yang mengikuti pembelajaran konvesional. Dari analisis uji-t rerata hasil belajar diperoleh nilai signifikansi ( $\mathrm{sig}$ ) $0.00<0,05$

\section{DAFTAR PUSTAKA}

[1] Martiani, K. (2012). Pengaruh Model Pembelajaran Kooperatif Tipe Struktural Think Pair Share Dan Numbered Heads Together Terhadap Self Efficacy Peserta Didik: Studi Kuasi Eksperimen pada Mata Universitas Pendidikan Indonesia. repository.upi.edu.

[2] Purwaningsih, D. dan Pujianto. (2010). Blended Cooperative E-Learning (BCeL) Sebagai Sarana Pendidikan Penunjang Learning Community. Jurusan Pendidikan Fisika FMIPA Universitas Negeri Yogyakarta.

[3] Sanjaya, W. (2006). Strategi Pembelajaran; Berorentasi Standar Proses Pendidikan. Bandung: Prenada Media Group.

[4] Sukri, S. Anuar, A. Ting, K. (2003). Kajian Mengenai Penggunaan E-Pembelajaran (E-Learning) Di Kalangan Pelajar Jurusan Pendidikan Teknikal Dan Vokasional Di Institusi Pengajian Tinggi (IPTA) Negeri Johor. Pendidikan dan Kejuruteraan Fakulti Pendidikan Universiti Teknologi Malaysia.

[5] Slavin, R. E. (1997). Cooperative learning: Theory, Riset dan Praktik. Bandung: Nusa Media.

[6] Sugiyono. (2009). Metode Penelitian Pendidikan Pendekatan Kuantitatif, Kualitatif, $R \& D$. Bandung: Alfabeta. 